\title{
AVALIAÇÃO DO INCREMENTO EM DIÂMETRO DO MOGNO (Swietenia macrophylla) EM UM SAF - RURÓPOLIS-PARÁ
}

\author{
Itabira Jaguaraçú Ricardo Sanches ${ }^{1}$ \\ Carla Alessandra dos Santos ${ }^{2}$ \\ Stefania Marques Pimentel ${ }^{3}$ \\ Rebyson Bissaco Guidinelle ${ }^{4}$ \\ Jociane Rosseto de Oliveira Silva ${ }^{5}$ \\ Ivan Cleiton de Oliveira Silva ${ }^{6}$ \\ Júlio Cesar Wojciechowski ${ }^{7}$ \\ Vinícius Augusto Morais ${ }^{8}$
}

Resumo: Esse trabalho tem como objetivo avaliar o incremento em diâmetro da espécie Swietenia machophylla em um sistema Agroflorestal. Em uma área de 1 ha foram alocadas 5 parcelas de 12 × $24 \mathrm{~m}$. As medições foram realizadas em três ocasiões, sendo: Janeiro de 2014, Janeiro de 2015 e Julho de 2015. Para construção dos histogramas de frequência foram testados os métodos de Sturges e "empírico". Em um segundo plano histogramas de crescimento foram elaborados tendo em vista a visualização dos diâmetros de cada indivíduo para análise do incremento em diâmetro. O melhor resultado para construção dos histogramas foi o método "empírico", pois apresentou menor erro. O incremento no DAP médio foi de $0,58 \mathrm{~cm}$ entre as três medições, no primeiro período o incremento em diâmetro foi de 11,32, no segundo $11,76 \mathrm{~cm}$ e no último $11,90 \mathrm{~cm}$.

Palavras-chave: Manejo florestal; distribuição de classes diamétricas; Sturges; Swietenia macrophylla.

\footnotetext{
${ }^{1}$ Engenharia Florestal/UNEMAT, Brasil. E-mail: ita-bira@hotmail.com.

2 Engenharia Florestal/UNEMAT, Brasil. E-mail: karlalessandra_af1@hotmail.com.

3 Pós-graduação em Ciências Florestais/ UFES, Brasil. E-mail: stefania.marques@hotmail.com.

4 IFES, Brasil. E-mail: rebysonguidinelle@gmail.com.

5 Engenharia Florestal/UNEMAT, Brasil. E-mail: jorosseto@hotmail.com.

${ }^{6}$ Engenharia Florestal/UNEMAT, Brasil. E-mail: ivanunemataf@unemat.br.

7 Engenharia Florestal/UNEMAT, Brasil. E-mail: juliocw@unemat.br.

8 Engenharia Florestal/UNEMAT, Brasil. E-mail: viniciusmorais@unemat.com.
} 